\title{
STATUS OF WATER RESOURCES IN NEPAL AND EXISTING USE IN IRRIGATION
}

\author{
Govinda Prasad Poudel*1
}

\begin{abstract}
The surface water available in the country is estimated to be about 225 billion cu.m per annum, out of which only 15 billion cu.m per annum is in use. In addition to surface water, a large volume of water is available in the shallow and deep aquifers which are estimated to be 8.8 billion cu.m annually which can be used for irrigation and domestic water supplies. At present less than $\mathbf{5 0 \%}$ of the cultivated area has intermittent irrigation facilities and less than $20 \%$ of cultivated area has year round irrigation.Nepal's economy is largely based on agriculture however, Nepalese agriculture is mainly rain fed and agriculture production in both rain fed as well as irrigated areas are being badly affected due to droughts, flooding, erratic rainfall, and other extreme weather events. It is necessary that the modern agriculture practice with the help of year round irrigation we can increase the GDP and provides greater employment opportunities and ultimately we can do sustainable agriculture development. Present water consumption rate is less than $8 \%$ of the country's water potential for irrigation sector. This water consumption rate is very low for our country. This consumption rate can be increase by making a comprehensive study and implementation plan by making multipurpose reservoir type irrigation project for maximum use of available water resources. Year round irrigation scheme also become great tool to get optimum economic development in agricultural sector and maximum crop yield.
\end{abstract}

\section{INTRODUCTION}

Currently, about $10 \%$ of total precipitation in Nepal falls as snow, about $23 \%$ of Nepal's total area lie above the permanent snowline of $5000 \mathrm{~m}$., about $3.6 \%$ of Nepal's total areas are covered by glaciers. There are 3,252 glaciers covering an area of 5,323 sq.km with an estimated ice reserve of $481 \mathrm{Cu} . \mathrm{km}$. There are 2323 glacial lakes in Nepal covering an area of 75 sq. km. Nepal is gifted with rich water resources. The bodies of water here are regarded as the key focused natural resources with the potential to act as the instrument for the development and economic growth of the country. There are about 6000 rivers in Nepal and the total drainage area of these rivers is around $194,471 \mathrm{~km} 2,76 \%$ of which lies within Nepal. The development of Nepal's water resources could generate hydroelectric power, supply water for irrigation, domestic and industrial uses. But till date this huge water resources can't use properly to irrigation and other related sectors. So this study is important for future water resources planning and management in Nepal.

Lecturer, Tribhuvan University, IOE, Thapathali campus

Corresponding author

E-mail : poudelgpd@gmail.com 


\section{Material and Methods}

The river basins in Nepal, Hydrologic Zones, Surface and Ground Water Resources and its Utilization in Irrigation development are the main materials of this research. This is based on survey and review of past studies in various times in various organizations. The detail studies in the past are describe below.

River Systems in Nepal: The Gandaki, Koshi, Karnali and Mahakali, are the four main river systems. They originate in the Himalaya and carry snow fed flows with significant discharge even in the dry Season. These rivers are perennial and have tremendous potential as a source of irrigation and hydropower development. The Babai, West Rapti, Bagmati, Kamala, Kankai and the Mechi are medium rivers. These rivers originate in the Midlands or the Mahabharat Range and are fed by precipitation as well as groundwater regeneration including springs. These rivers also are perennial but are commonly characterized by a wide seasonal fluctuation in discharge. There are a large number of small rivers in the Terai which mostly originate in the Siwalik Range. These rivers are seasonal with little flow during the dry season which renders them unsuitable for year round irrigation or hydropower generation without surface storage. The rivers in Nepal are characterized by wide, seasonal fluctuation of flow. The monthly flows generally reach their maximum in July-August and decline to their minimum in February-March. About $80 \%$ of the total flow occurs during June - October and the rest during the remaining months.

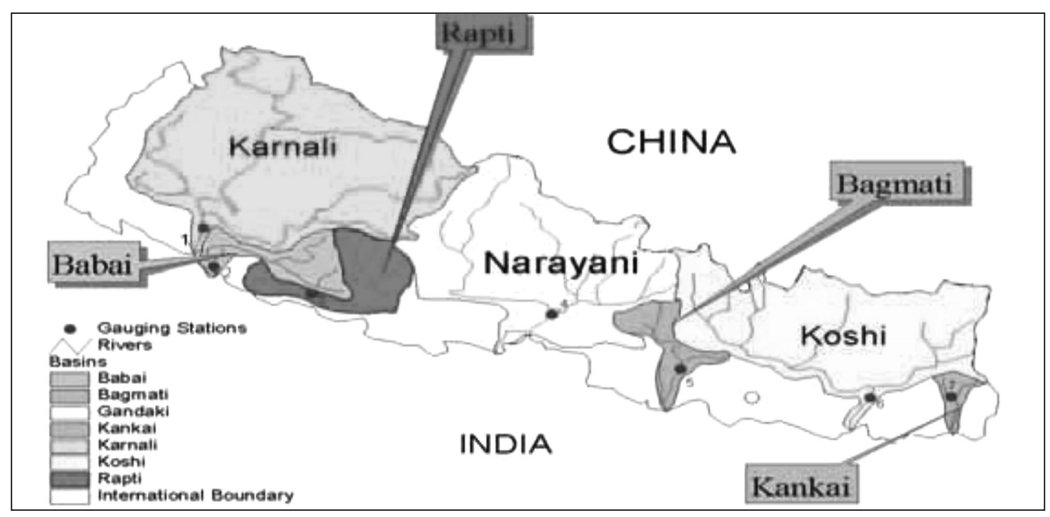

Figure 1: The river basins in Nepal (Prepared by: A Pokhrel and N.M. Shakya. 2010)

\section{Hydrologic Zones in Nepal}

The climatic and topography variation is extremely high in Nepal. Nepal's topography is inclined southwards towards the Ganges River. All the four major river systems predate the uplift of the main Himalayan Ranges and have kept pace with the uplift so that they now cut through the ranges in deep valleys. In the mountain and midland zones, the geology tends to promote rapid run-off resulting in a dense network of small, steep streams draining into the major rivers. In contrast, the geology promotes groundwater storage in the Siwalik Hills, on the Terai margins and the inner Terai. The run-off is concentrated in the monsoon season. The contribution of snowmelt to the total run-off occurs mainly from March to July. 
In catchments below $3000 \mathrm{~m}$, there is no significant contribution from snow. Based on the climatic features and the responses of the basins, seven hydrological zones are identified in Nepal (1). They are (a) Mountain Catchments (b)Hills to the north of the Mahabharat Range, rivers rising north of the Siwaliks, the inner Terai (c) Pokhara, Nuwakot, Kathmandu, the Sun Koshi tributaries (d) Lower Tamur Valley(e) River draining the Mahabharat Range(f) Kankai Mai Basin; and(g) Rivers draining from the Churia Range to the Terai.

\section{Surface Water Resources of Nepal}

The surface water available in the country is estimated to be about 225 billion $\mathrm{m} 3$ per annum, equivalent to an average flow of 7,125 m3/s (3). The total drainage area of these rivers is around $194,471 \mathrm{~km} 2,76 \%$ of which lies within Nepal. It is seen that around $78 \%$ of the average flow in the country is available in the four major basins, $9 \%$ in the medium basins and $13 \%$ in the several small southern rivers of the Terai. As the southern slopes of the Mahabharat Range, the Himalayan Range and the eastern two-third of the country receive the maximum precipitation, there is more contribution from the flow of these catchments. About $74 \%$ of the total annual surface flow occurs in the four months of June - September. The $42 \%$ of the population resides in the major basins, $18 \%$ in the medium and $40 \%$ in the Terai region covered by the southern rivers. Irrigation demand is major conjunctive use in a basin. The basin-wise distribution of population and water availability has resulted in some basins having excessively surplus water availability and some basins with deficit water availability. This renders the planning and management of water resources an additionally complex task. The glaciers in the High Himalayan region of Nepal are very important features that sustain water availability in the region. It is particularly so during the lean flow seasons when the melt-water contribution is crucial for the supporting of human activities and ecosystem services in both these areas and downstream. The glaciers in the nine basins (as shown in Figure 2) contain approximately $70 \%$ of the total glacier surface area in the Nepal Himalaya. The glacier contribution to the total stream flow of the basins in which they are situated varies widely among basins - from approximately $30 \%$ in the Budhi Gandaki basin to approximately $2 \%$ in the Likhu Khola Basin.

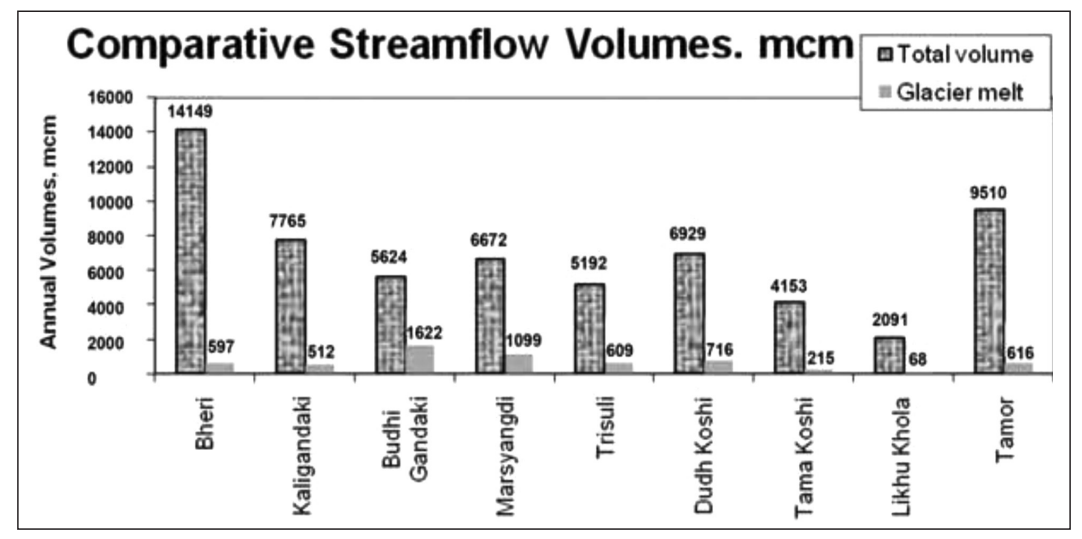

Figure 2: A graph, showing the relative annual stream flow, in million cubic meters, $m \mathrm{~cm} / y r$ (World Bank, 2009) 


\section{Groundwater and its Utilization}

The available information show that a good potential for groundwater extraction exists in the Terai and the inner valleys in the hills and mountains. Much of the Terai and some parts of the Siwalik valleys are dominated by shallow or deep aquifers, many of which are suitable for exploitation as sources of irrigation and drinking waters. Their annual recharge estimates range from 124 to $685 \mathrm{~mm}$. The corresponding volume of water available for groundwater extraction is estimated to be between 5.8 BCM to $12 \mathrm{BCM}$. However, based on the measurement of the seasonal fluctuations in the water table in shallow tube-wells, the groundwater reserve is reported to be about $8.8 \mathrm{BCM}$ annually. The groundwater resource estimates are mainly available for the Kathmandu Valley, the Inner Terai valleys like Udayapur, Chitwan, Deukhuri, Dang, Surkhet and the main Terai. However, the groundwater estimates for the springs and dug-wells in the hills and mountains have not been made up-to-date. There have been various estimates of the groundwater resources. In the Kathmandu Valley, the annual rechargeable estimates vary from $4.75 \mathrm{mcm}$ to 13.65 mom per annum. The five inner Terai valleys listed above are estimated to contain good groundwater potential. The estimates for Chitwan, Deukhuri and Dang are about 136-421 mcm/annum, 133 - $181 \mathrm{mcm} /$ annum and 130-140 mcm/annum(from shallow tube-wells alone) respectively (3).

\section{Irrigation Potential and Development}

Irrigation Potential and Development: Irrigation is a major issue in the development of Nepal. It is the largest water use sub-sector, affects the life of many people involved in agriculture, the major contributor to the Gross Domestic Product (4) and a major factor for maintaining food security in the country. The government, from the very beginning, has wisely recognized this fact and given due importance to irrigation, both in its yearly and five-year plans. Given the importance of irrigation and the large investments already made and planned for the future, the effectiveness of water delivery and its ultimate sustainability are of major concern. Nepal has a cultivated area of 2,642,000 ha (18\% of its land area). Out of this, two-third (1,766,000 ha) is potentially irrigable. At present, $42 \%$ of the cultivated area has irrigation of some sorts but only $17 \%$ of the cultivated area has year-round irrigation (i.e. only $41 \%$ of the irrigated area gets year-round irrigation). In the Terai, $82 \%$ of the total irrigated area $(889,000 \mathrm{ha})$ is through surface irrigation and the remaining 18\% through groundwater. Most of the irrigated areas (and the future potential) are situated in the fertile lowlands of the Terai. It is estimated that the existing irrigation schemes contribute approximately $65 \%$ of the country's current agriculture production (3). Around $90 \%$ of the command area is covered during the wet season. But, the coverage is only around $25 \%$ during the dry season. This is due to the high seasonal variation in the water available in the streams. The Agriculture Perspective Plan (APP) estimated the water use for irrigation with a total of 17,000 million cubic meters which is less than $8 \%$ of the Country's total water resource potential 


\section{Results/Discussion}

From the survey and past studied it is shows that the surface water available in the country is estimated to be about 225 billion cu.m per annum, out of which only 15 billion cu.m per annum is in use. In addition to surface water, a large volume of water is available in the shallow and deep aquifers which are estimated to be 8.8 billion cu.m annually which can be used for irrigation and domestic water supplies. At present less than $50 \%$ of the cultivated area has intermittent irrigation facilities and less than 20 $\%$ of cultivated area has year round irrigation. Only less than $8 \%$ of the country's water potential is used for irrigation. Nepal's economy is largely based on agriculture, however, Nepalese agriculture is mainly rain fed and agriculture production in both rain fed as well as irrigated areas are being badly affected due to droughts, flooding, erratic rainfall, and other extreme weather events. It is necessary that the modern agriculture practice with the help of year round irrigation we can increase the GDP and provides greater employment opportunities and ultimately we can do sustainable agriculture development. Without optimum use of water resources in agriculture sector we can't grow national economy and employment opportunity. Therefore it is urgent to use optimum water resources by constructing reservoir type of headworks for irrigation system and providing year round irrigation to the possible agriculture land throughout the country.

\section{Conclusions}

Present water consumption rate is less than $8 \%$ of the country's water potential for irrigation sector. The water consumption rate is negligible therefore it is necessary to make a comprehensive study and implementation of irrigation project for year round irrigation scheme to get optimum economic development and optimum use of water resources to get maximum crop yield.

\section{Acknowledgements}

I would like to express my sincere gratitude to Dr. Surya Adhikari, Chief of Journal publication committee IOE Thapathali Campus, who as a key person to encourage worked hard to bring out this publication. ${ }^{2}$

(1) Shah SG, Singh GN. 2001. Irrigation Development in Nepal Investment, Efficiency and Institution. Research Report Series No. 47, Winrock International, Kathmandu, Nepal.

(2) Shakya NM. 2002. Hydrological changes assessment and its impact on hydropower projects of Nepal. In: Proceedings of the consultative Workshop on Climate Change Impacts and Adaptation Options in Nepal's Hydropower Sector with Focus on Hydrological Regime Changes including GLOF, DHM and Asian Disaster Preparedness Center, Kathmandu (2002).

(3) WECS. 2003. Water Resource Strategy Nepal. Water and Energy Commission Secretariat Kathmandu, Nepal.

(4) MoF. 2005. Economic Survey- Fiscal Year 2004/05. Ministry of Finance, Nepal, Kathmandu, pp. 288.

(5) ADB/ICIMOD. 2006. Environment Assessment of Nepal: Emerging Issues and Challenges.Asia Development Bank/ International Centre for Integrated Mountain Development. Kathmandu,

(6) World Bank. 2009. Glacier Retreat in the Nepal Himalaya: An Assessment of the Role of Glaciers in the Hydrologic Regime of the Nepal Himalaya. Prepared for the South Asia Sustainable Development (SASDN) Offi ce, Environment and Water Resources Unit.

(7) WECS. 2011. Water Resources of Nepal in the Context of Climate Change 